\title{
A PROCEDURE FOR TESTING POLYGRYSTALLINE ICE IN UNIAXIAL TENSION
}

\author{
By R. W. Lee, J. H. Currier,* P. N. Lim, and E. M. Schulson
}

(Thayer School of Engineering, Dartmouth College, Hanover, New Hampshire 03755, U.S.A.)

Abstract. A procedure is described for testing ice in tension. It incorporates a one-piece lucite mold, two carpeted "Synthane" end-caps and a pair of yokes and ball joints. Use of the procedure has resulted in a successful test rate greater than $80 \%$

RÉsumé. Un procédé de test de la glace polycristalline en tension uniaxiale. On décrit un procédé de test de la glace en tension. Il est constitué d'un moule de plastique transparent d'une seule pièce, de deux flasques de fermeture carpetées en "synthane" et d'une paire de cardans à bille. L'utilisation de

This note outlines a procedure, developed and successfully employed over the past three years, to test polycrystalline ice in uniaxial tension. Details beyond those presented here may be obtained from Currier (unpublished), Currier and others (1983) and from Lim (unpublished); applications and test results at $T=-20$ to $-5^{\circ} \mathrm{C}$ at $10^{-6} \mathrm{~s}^{-1}$ are described by Currier and Schulson (1982) and by Schulson and others (1984).

The brittle nature of ice when tested in tension requires (1) a capability to consistently produce accurately dimensioned samples and (2) a method of applying a pure uniaxial tensile stress.

The method used to prepare samples is similar to that developed by Cole (1979). A cylindrical mold is charged with seed grains, evacuated, flooded with degassed and deionized water, and frozen radially inward. During freezing the system remains open to water flow to flush impurities and to avoid the development of internal stresses due to the expansion of freezing water.

The mold (Fig. 1) consists of a one-piece lucite (polymethyl-methacrylate) cylinder into which fit lucite alignment caps. Right circular cylinders of

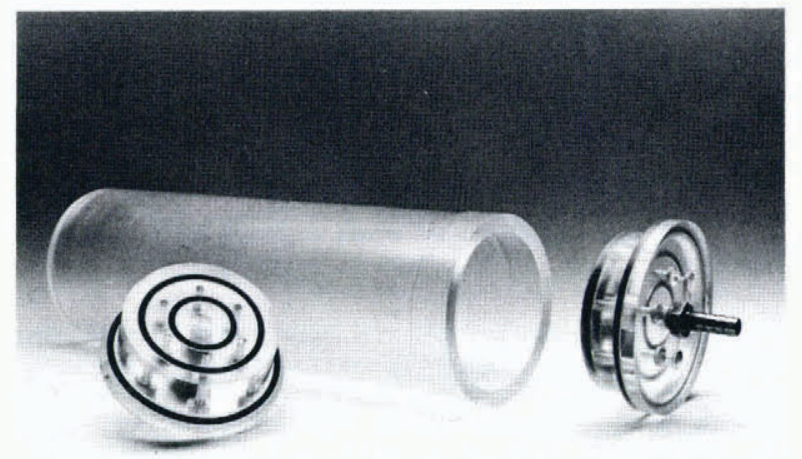

Fig. 1. One-piece lucite cylinder with alignment caps. Total cylinder length is $35 \mathrm{~cm}$.

*Now with ARCO Oil and Gas Company, Dallas, Texas, U.S.A. ce montage a conduit à un test satisfaisant avec un taux de déformation supérieur à $80 \%$.

Zusammenfassung. Ein Verfahren zur Prüfung polykristallinen Eises unter einachsiger Zugspannung. Zur Prüfung von Eis unter Zugspannung wird ein Verfahren angegeben. Es benutzt eine Gussform aus einem Stück, zwei beschichtete "Synthane"-Endkappen und ein Paar von Bügeln und Kugelgelenken. Die Anwendung des Verfahrens führte in mehr als $80 \%$ der Versuche zum Erfolg.

ice, $9.1 \mathrm{~cm}$ in diameter and $23.1 \mathrm{~cm}$ in length, are extracted by warming the cylinder surface gently with a warm-air gun and by pushing by hand. Careful machining insures that the inside diameter of the cylinder is uniform to $\pm 0.0013 \mathrm{~cm}$, that the ends are parallel and perpendicular to the wall and that the 0 -ring bearing surfaces on each alignment cap are parallel.

To apply the tensile load, linen-based phenolic (Synthane) end-caps, as proposed by Mellor (Schwarz and others, 1981, p. 250), are attached to each alignment cap (Fig. 2). Upon freezing, they become integral parts of the sample. The end-caps are $9.1 \mathrm{~cm}$ in diameter (the sample diameter) and $3.2 \mathrm{~cm}$ in thickness. A threaded hole, $2.54 \mathrm{~cm}$ in diameter, in the center of each end-cap allows attachment to the testing machine.

Initially the ice was frozen directly to end-caps whose bonding surfaces had been roughened by passing a single-point threading tool across the surface as the cap was rotated in a lathe. While this method provided a sufficiently strong bond between ice and endcaps, the fracture surface was typically "domed" and, although entirely within the ice, very near an endcap.

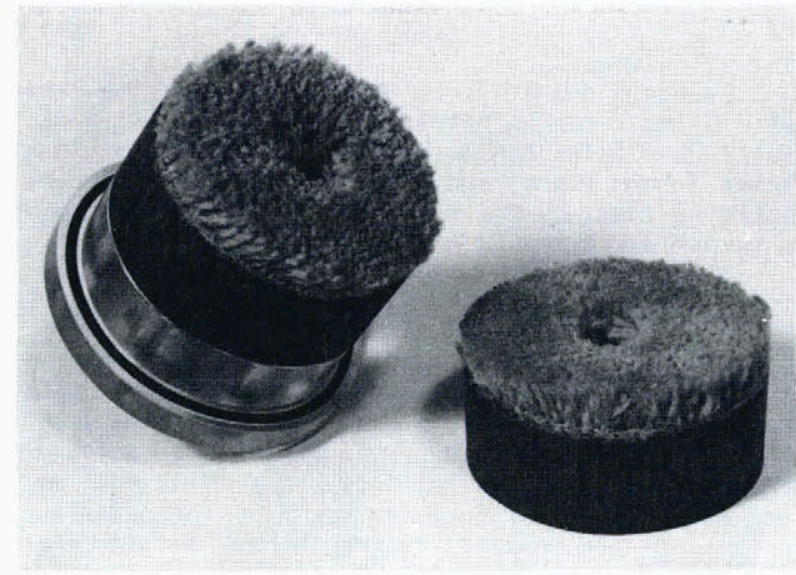

Fig. 2. Jute-backed carpet epoxied to synthane endcaps. 
The domed surface indicated the presence of induced shear stresses at the ice/end-cap interface owing to differences in the elastic moduli and thermal expansion coefficients of ice and Synthane (for a further analysis see Currier and others, 1983, p. 6-8). When combined with the applied tensile stress, shear stresses, if not avoided, produce a principal stress greater than the applied stress and the sample fractures prematurely.

It was found that jute-backed carpet epoxied to each roughened end-cap surface yielded fracture surfaces normal to the tensile axis. The addition of a carpet layer provides sufficient compliance at the ice/end-cap interface to prevent the development of large shear stresses. In addition, it enhances the strength of the ice/end-cap bond. The absence of shear stresses at the end zones also prevents the need for reducing the cross-sectional area within the gage section: only right circular cylinders need be tested.

To insure the application of purely uniaxial load, a steel assembly consisting of a ball-joint and yoke was developed to connect the sample end-caps to the testing machine (Fig. 3). The ball-joints, containing

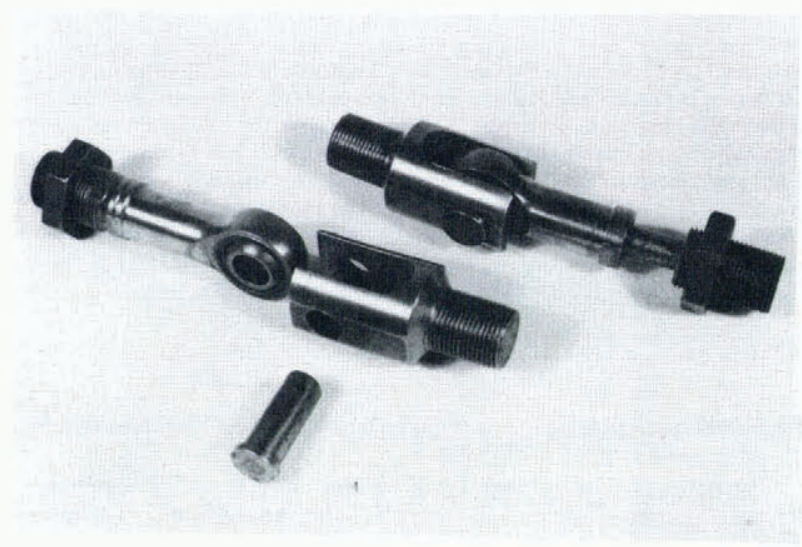

Fig. 3. Yoke and ball-joint assembly. Steel connecting pin is $4.1 \mathrm{~cm}$ in length.

a sintered iron ball which rotates freely in a carburized steel race, correct small vertical misalignments and remain threaded into the crossheads of the testing machine. A steel yoke and pin were machined for each ball-joint such that the iron ball fitted snugly into the yoke and the pin slid through to provide a rapid connection between yoke and ball-joint.
In this way the ice sample becomes the "weak link" in a chain significantly more rigid than the cable system proposed by Schwarz and others (1981, p. 24950).

Until care was taken to control circumferential variations in end-cap thickness and overall sample dimensions, less than one half of the specimens resulted in successful tests. (A successful test results in fracture normal to the tensile axis within the central third of the sample.) However, once variations in end-cap thickness were reduced to $\pm 0.0013 \mathrm{~cm}$ and a mold was developed capable of consistently controlling sample length to $\pm 0.004 \mathrm{~cm}$ and diameter to \pm $0.0013 \mathrm{~cm}$, greater than $80 \%$ of the samples prepared and tested using this procedure have ended in successful tests. This experience indicates the extreme importance of sample alignment when testing ice in tension.

\section{ACKNOWLEDGEMENTS}

We wish to thank D. Cole and M. Mellor of the U.S. Army Cold Regions Research and Engineering Laboratory, Hanover, New Hampshire, for valuable assistance during the early stages of this work. Also, we acknowledge financial support from the U.S. Army Research Office, Contract No. DAAG 29-80-C-0064, and from the Mobil Corporation.

\section{REFE RENCES}

Cole, D.M. 1979. Preparation of polycrystalline ice specimens for laboratory experiments. Cold Regions Science and Technology, Vol. 1, No. 2, p. 153-59.

Currier, J.H. Unpublished. The brittle to ductile transition in polycrystalline ice under tension. [M.Sc. thesis, Dartmouth College, 1981.]

Currier, J.H., and Schulson, E.M. 1982. The tensile strength of ice as a function of grain size. Acta Metalluegica, Vol . 30, No. 8, p. 1511-14.

Currier, J.H., and others. 1983. A study of the tensile strength of ice as a function of grain size, by J.H. Currier, E.M. Schulson, and W.F. St. Lawrence. CRREL Report (Hanover, N.H.) 83-14.

Lim, P.N. Unpublished. The effects of temperature and grain size on the tensile strength of ice. [M.Sc . thesis, Dartmouth College, 1983.]

Schulson, E.M., and others. 1984. A brittle to ductile transition in polycrystalline ice under tension, by E.M. Schulson, P.N. Lim, and R.W. Lee. Philosophical Magazine A, Vol. 49, No. 3, p. 353-63.

Schwarz, J., and others. 1981. Standardized testing methods for measuring mechanical properties of ice, by J. Schwarz [and 6 others]. Cold Regions Science and Technology, Vol. 4, No. 3, p. 245-53. 